\section{A Comparison of Staining Techniques for Somatic Chromosomes of Strawberry}

\author{
Henry R. Owen and A. Raymond Miller \\ Department of Horticulture, The Ohio State University, Ohio Agricultural \\ Research and Development Center, 1680 Madison Avenue, Wooster, \\ OH 44691-4096
}

Additional index words. cytology, Fragaria $\times$ ananassa, ploidy level, root-tip squashes

\begin{abstract}
A factorial combination of pretreatments, fixatives, and stains was examined to identify the best available method for staining the chromosomes of strawberry (Fragaria $x$ ananassa Duch. 'Chandler') root-tip cells. Three pretreatments ( $a$-bromonaphthalene, p -dichlorobenzene, and 8-hydroxyquinoline), three fixatives (Farmer's fluid, Carnoy's fluid, and Newcomer's fluid), and five stains (acetocarmine, alcoholic hydrochloric-acid carmine, altered carbol fuchsin, lacto-propionic orcein, and leucobasic fuchsin) were tested. Pretreatment with either $a$-bromonaphthalene (saturated aqueous) or 8-hydroxyquinoline ( $2 \mathrm{~mm}$ ) for 5 hours at 14C, overnight fixation in Farmer's fluid, hydrolysis in $1 \mathrm{NHCl}$ (15 minutes at 60C), and staining with altered carbol fuchsin produced chromosome preparations superior to other treatment combinations. Treatment with a-bromonaphthalene, Farmer's fluid, and alcoholic hydrochloric-acid carmine (2 days at $25 \mathrm{C}$ ) also produced acceptable chromosome preparations.
\end{abstract}

A simple, rapid, and reliable chromosome staining procedure for determining chromosome number of root-tip meristematic cells is needed at several points during a plant-breeding program. For example, it is necessary to confirm the ploidy level in plants regenerated from anther or ovary culture, cell fusions, or callus culture or to identify haploid genotypes, heterokaryons, or spontaneously doubled genotypes. Determining ploidy level in somatic cells of strawberry cultivars is hampered by their polyploid status $(2 \mathrm{n}=8 \mathrm{x}=56)$, small chromosome size, and small volume of mitotic cells (Iwatsubo and Naruhashi, 1989). These characteristics make it difficult to prepare clearly defined and well-spread chromosomes that are visible in a single focal plane. Bringhurst and Kahn (1963) reported a chromosome staining procedure for pentaploid Fragaria hybrids using a $p$-dichlorobenzene pretreatment, 3 ethanol $(\mathrm{EtOH}): 1$ propionic acid fixation, and staining with alcoholic hydrochloric-acid carmine at $0 \mathrm{C}$ for a minimum of 1 week. Niemirowicz-Szczytt and Zakrzewska (1981) examined Fragaria $\times$ ananassa root tips after fixing them in Carnoy's fluid and staining them in acetocarmine at $4 \mathrm{C}$ for 1 week. Iwatsubo and Naruhashi (1989) analyzed the karyotypes of three Fragaria species ( $F$. iinumae Makino, $F$. nipponica Makino, and $F$. vesca L.) using an 8-hydroxyquinoline pre-

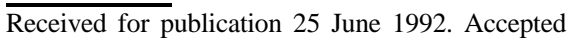
for publication 19 Oct. 1992. Supported in part by state and federal funds appropriated to the Ohio State Univ., Ohio Agr. Res. and Dev. Ctr., Wooster. Manuscript no. 181-92. The cost of publishing this paper was defrayed in part by the payment of page charges. Under postal regulations, this paper therefore must be hereby marked advertisement solely to indicate this fact.
}

treatment, 3 EtOH : 1 acetic acid fixation, and either leucobasic fuchsin or lacto-propionic orcein staining. In earlier studies in our laboratory, these procedures did not produce adequate staining intensity and contrast between the chromosomes and the surrounding cytoplasm for several Fragaria $\times$ ananassa cultivar preparations. The objective of this study, therefore, was to examine a factorial combination of three pretreatments, three fixatives, and five stains and evaluate their ability to produce effective chromosome preparations.

Field-propagated runners were grown in coarse sand in half-liter pots in a greenhouse with supplementary lighting (high-pressure sodium lamps, 16-hphotoperiod) for 2 weeks. Root tips $(0.5$ to $1.0 \mathrm{~cm})$ were collected between 1000 and $1200 \mathrm{HR}$ and immediately placed in one of the following pretreatments: 1) a saturatedaqueous solution of $a$-bromonaphthalene, 2) a saturated aqueous solution of $p$-dichlorobenzene, or 3) $2 \mathrm{~mm} 8$-hydroxyquinoline. After pretreatment for $5 \mathrm{~h}$ at $14 \mathrm{C}$ in darkness, all roots were transferred to one of the following three fixatives and incubated for $16 \mathrm{~h}$ at $25 \mathrm{C}$ : 1)Carnoy's fluid [6ethanol 95\% : 3chloroform : 1 acetic acid; Darlington and La Cour ( 1962)], 2) Farmer's fluid [3 ethanol $95 \%: 1$ acetic acid; Berlyn and Miksche (1976)], or 3) Newcomer's fluid [6 isopropyl alcohol : 3 propionic acid : 1 petroleum ether : 1 acetone : 1 dioxane; Newcomer ( 1953)]. After fixation, the roots were transferred to $70 \% \mathrm{EtOH}$, incubated at $4 \mathrm{C}$, and stained within 2 days. Five stains were examined for a total of 45 treatments (three pretreatments $\times$ three fixatives $\times$ five stains): 1) acetocarmine containing iron acetate mordant (Darlington and La Cour, 1962), 2) alcoholic hydrochloric acid carmine without mordant (Snow, 1963), 3) altered carbol fuchsin (Martens and Reisch, 1988), 4) lacto-pro- pionic orcein (Dyer, 1963), and 5) leucobasic fuchsin (Lillie, 1951). All roots, except those to be stained with alcoholic hydrochloric-acid carmine, were hydrolyzed in $1 \mathrm{~N} \mathrm{HCl}$ for 15 $\mathrm{min}$ at $60 \mathrm{C}$ and then rinsed in cold (4C) distilled water before staining. Roots stained in alcoholic hydrochloric-acid carmine were destained in $45 \%$ acetic acid for $10 \mathrm{~min}$ at $60 \mathrm{C}$ before squashing. Five root tips were examined from each treatment.

Stained root tips (1 to $2 \mathrm{~mm}$ ) were placed on a slide, tapped for $30 \mathrm{sec}$ with the rounded end of a glass rod, and squashed under a cover slip by very firm downward pressure from a fresh pencil eraser. Root tips were excised and squashed 30 to 90 min after staining, except roots stained in acetocarmine or alcoholic hydrochloric acid carmine. Roots stained with carmine were incubated for 2 days at $25 \mathrm{C}$ before squashing. Slides were sealed with melted paraffin and examined and photographed at $\times 1000$ magnification using an Olympus (Lake Success, N.Y.) BH-2 compound microscope under bright-field illumination through a green iris filter (Olympus 45G533).

Preparations were scored on a three-point scale for relative staining intensity and contrast between the chromosomes and the surrounding cytoplasm (Table 1). In most cases pretreatment with a-bromonaphthalene produced preparations equal or superior to pretreatment with 8-hydroxyquinoline or $p$-dichlorobenzene. Pretreatment with 8-hydroxy-quinoline generally resulted in chromosome preparations that were clearly defined, but less condensed than root tips pretreated with a-bromonaphthalene. Pretreatment with $p$-dichlorobenzene in many cases resulted in insufficient chromosome condensation and, thus, reduced definition. Given its effectiveness and ease of preparation, a-bromonaphthalene, therefore, is recommended for strawberry root pretreatment.

Fixation in Farmer's fluid was slightly better than in Carnoy's fluid and it was substantially better than in Newcomer's fluid, based on microscopic examination of stained samples. In some cases, fixation in Newcomer's fluid resulted in fractured chromosomes. Farmer's fluid and Carnoy's fluid, however, do not store well and must be prepared fresh each time they are used. Given the results of this study, however, Farmer's fluid is recommended.

Staining with altered carbol fuchsin resulted in superior chromosome preparations, particularly if combined with $a$-bromonaphthalene or 8-hydroxyquinoline pretreatment and fixation in Farmer's or Carnoy's fluid (Fig. 1). These results are consistent with those of Martens and Reisch (1988), who determined that an altered form of carbol fuchsin was superior to other stains for examining chromosomes of grape (Vitis vinifera $\mathrm{L}$.) $(2 \mathrm{n}=$ $2 \mathrm{x}=38$ ). Staining with alcoholic hydrochloric acid carmine produced acceptable chromosome preparations, but their intensity in some cases was inferior to preparations stained with carbol fuchsin. Incubating root tips in alcoholic 
Table 1. Relative chromosome staining intensity and contrast between chromosomes and cytoplasm of strawberry root-tip squashes as influenced by pretreatment, fixative, and staining method. ${ }^{2}$

\begin{tabular}{|c|c|c|c|c|}
\hline Pretreatment & Fixative & Stain & Intensity & Contrast \\
\hline \multirow[t]{15}{*}{$\alpha$-Bromonaphthalene } & Farmer & Acetocarmine & 1 & 2 \\
\hline & & Alcoholic $\mathrm{HCl}$ carmine & 3 & 3 \\
\hline & & Leucobasic fuchsin & 2 & 2 \\
\hline & & Carbol fuchsin & 3 & 3 \\
\hline & & Lacto-propionic orcein & 2 & 2 \\
\hline & Carnoy & Acetocarmine & 1 & 2 \\
\hline & & Alcoholic $\mathrm{HCl}$ carmine & 2 & 2 \\
\hline & & Leucobasic fuchsin & 2 & 2 \\
\hline & & Carbol fuchsin & 2 & 3 \\
\hline & & Lacto-propionic orcein & 2 & 2 \\
\hline & Newcomer & Acetocarmine & 1 & 2 \\
\hline & & Alcoholic $\mathrm{HCl}$ carmine & 2 & 2 \\
\hline & & Leucobasic fuchsin & 1 & 1 \\
\hline & & Carbol fuchsin & 3 & 1 \\
\hline & & Lacto-propionic orcein & 2 & 2 \\
\hline \multirow[t]{15}{*}{$p$-Dichlorobenzene } & Farmer & Acetocarmine & 1 & 1 \\
\hline & & Alcoholic $\mathrm{HCl}$ carmine & 2 & 1 \\
\hline & & Leucobasic fuchsin & 1 & 1 \\
\hline & & Carbol fuchsin & 1 & 2 \\
\hline & & Lacto-propionic orcein & 1 & 1 \\
\hline & Carnoy & Acetocarmine & 1 & 1 \\
\hline & & Alcoholic $\mathrm{HCl}$ carmine & 1 & 1 \\
\hline & & Leucobasic fuchsin & 1 & 1 \\
\hline & & Carbol fuchsin & 1 & 1 \\
\hline & & Lacto-propionic orcein & 2 & 1 \\
\hline & Newcomer & Acetocarmine & 1 & 1 \\
\hline & & Alcoholic $\mathrm{HCl}$ carmine & 2 & 1 \\
\hline & & Leucobasic fuchsin & 1 & 1 \\
\hline & & Carbol fuchsin & 2 & 1 \\
\hline & & Lacto-propionic orcein & 2 & 1 \\
\hline \multirow[t]{15}{*}{ 8-Hydroxyquinoline } & Farmer & Acetocarmine & 1 & 2 \\
\hline & & Alcoholic $\mathrm{HCl}$ carmine & 2 & 2 \\
\hline & & Leucobasic fuchsin & 2 & 1 \\
\hline & & Carbol fuchsin & 3 & 3 \\
\hline & & Lacto-propionic orcein & 2 & 2 \\
\hline & Carnoy & Acetocarmine & 2 & 1 \\
\hline & & Alcoholic $\mathrm{HCl}$ carmine & 2 & 2 \\
\hline & & Leucobasic fuchsin & 2 & 1 \\
\hline & & Carbol fuchsin & 3 & 2 \\
\hline & & Lacto-propionic orcein & 2 & 2 \\
\hline & Newcomer & Acetocarmine & 1 & 1 \\
\hline & & Alcoholic $\mathrm{HCl}$ carmine & 2 & 2 \\
\hline & & Leucobasic fuchsin & 1 & 1 \\
\hline & & Carbol fuchsin & 2 & 2 \\
\hline & & Lacto-propionic orcein & 2 & 2 \\
\hline
\end{tabular}

${ }^{\mathrm{z}_{1}}=$ Poor, 2 = acceptable, 3 = best. Five root tips were examined from each treatment.

hydrochloric acid carmine for longer than 2 days or adding iron mordant to the formulation may increase its staining intensity. An advantage of using alcoholic hydrochloric acid carmine lies in its ability to soften root tips during staining and thus improve the ease of squashing (Snow, 1963). Staining with acetocarmine resulted in unacceptable preparations, particularly with respect to its low staining intensity. Pretreatment with $a$ bromonaphthalene before staining with acetocarmine improved the contrast of preparations, but it did not improve staining intensity. Staining chromosomes with leucobasic fuchsin was similar to staining them with acetocarmine, when values for staining inten- sity and contrast are combined; however, preparations stained with leucobasic fuchsin became overstained within $3 \mathrm{~h}$. Compared to the other stains, lacto-propionic orcein was intermediate in its ability to stain strawberry root tips effectively.

Overall, the best strawberry root-tip staining technique we examined for chromosome counting purposes consisted of a 5 -h pretreatment with a saturated aqueous solution of $a$ bromonaphthalene at 14C, 16-h fixation in Farmer's fluid at 25C, transfer to $70 \% \mathrm{EtOH}$, hydrolysis in $1 \mathrm{~N} \mathrm{HC} 1$ (15 min at 60C), and staining with altered carbol fuchsin.

By using this method and adjusting the focal plane during microscopic examination,

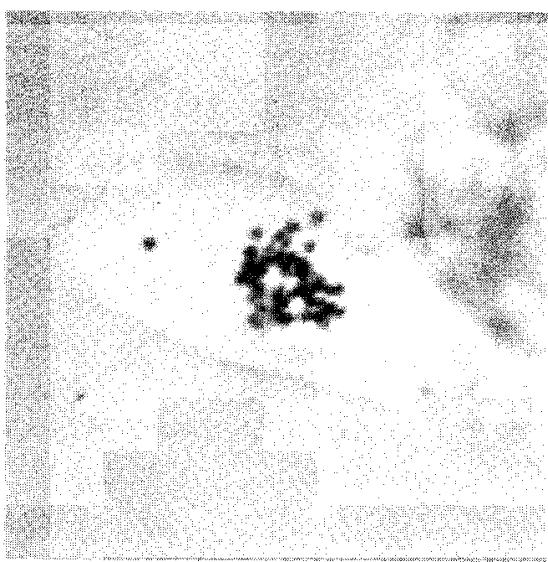

Fig. 1. Root-tip chromosomes of Fragaria $\times$ ananassa 'Chandler' pretreated with $\alpha$-bromonaphthalene, fixed in Farmer's fluid, and stained with altered

we obtained from freshly prepared samples a narrow range of chromosome numbers (52$57, \mathrm{n}=5$ ), sufficient to determine ploidy in octoploid strawberry $(2 n=8 x=56)$. We have used this technique subsequently with other strawberry cultivars, and lines developed from them, with good results. Other species, however, may benefit from further modification of these methods to obtain superior chromosome staining.

\section{Literature Cited}

Berlyn, G.P. and J.P. Miksche. 1976. Botanical microtechnique and cytochemistry. Iowa State Univ. Press, Ames.

Bringhurst, R.S. and D.A. Khan. 1963. Natural pentaploid Frugaria chiloensis- $F$. vesca hybrids in coastal California and their significance in polyploid Fragaria evolution. Amer. J. Bot. 50:658-661.

Darlington, C.D. and L.F. La Cour. 1962. The handling of chromosomes. 4th ed. Hafner Publishing Co., New York.

Dyer, A.F. 1963. The use of lacto-propionic orcein in rapid squash methods for chromosome preparations. Stain Technol. 38:85-90.

Iwatsubo, Y. and N. Naruhashi. 1989. Karyotype of three species of Fragaria (Rosaceae). Cytologia 54:493-497.

Lillie, R.D. 1951. Simplification of the manufacture of Schiff reagent for use in histochemical procedures. Stain Technol. 26:163-165.

Martens, M-H.R. and B.I. Reisch. 1988. An improved technique for counting chromosomes in grapes. HortScience 23(5):896-899.

Newcomer, E.H. 1953. A new cytological and histological fixing fluid. Science 118: 161.

Niemirowicz-Szczytt, K. and Z. Zakrzewska. 1981. Frugaria $\times$ ananassa anthers [sic] cultures. Bul. L'Acad. Polonaise Sci. Ser. Sci. Biol. 28(5):341347.

Snow, R. 1963. Alcoholic hydrochloric acid-carmine as a stain for chromosomes in squash preparations. Stain Technol. 38:9-13. 